\title{
Septo-optic dysplasia plus \\ clinical presentation and magnetic
resonance imaging findings
}

\author{
João Paulo K. Matushita Jr. ', Chan Tiel2 ${ }^{2}$ Raquel Ribeiro Batista ${ }^{3}$, \\ Marco Py ${ }^{4}$, Emerson L. Gasparetto ${ }^{5}$
}

Septo-optic dysplasia (SOD) is a heterogeneous developmental malformation characterized by optic nerve hypoplasia associated with dysgenesis of the septum pellucidum and other cerebral malformations. The clinical manifestations include psychomotor retardation, visual impairment, thermoregulatory disturbances, conjugated hyperbilirubinemia and seizures ${ }^{1-4}$. In 2000, Miller et al. ${ }^{2}$ first named the association of SOD and cortical dysplasia as SOD-plus. In this report, all the cases had severe clinical impairment, presenting global developmental delay and spastic motor deficits. Subsequent reports of SOD-plus also stressed the psychomotor development delay, spastic motor deficits and seizures seen in these patients, emphasizing the severity of the brain involvement. Recently, Kwak et al. ${ }^{5}$ reported a case of SOD-plus presenting with cortical dysplasia involving the insular cortex bilaterally. However, differently from all the previous reports, the patient had no signs or symptoms of cortical dysfunction, except for one episode of seizure.

We report an additional case of SODplus, which presented extensive cortical malformation, with no signs or symptoms of cortical dysfunction. We suggest that similar to the classical form of SOD, the clinical presentation in patients with SOD-plus can also range from mild to extremely severe.

\section{CASE}

A 19-year-old girl presented with headaches and low visual acuity. She had headaches since the childhood, with increasing intensity and frequency in the last months. The headaches were stitch and pressure like, involving the temporal region, and associated with neck pain. Anxiety and menstrual periods were related to worsening
Correspondence

Emerson L. Gasparetto

Av. Pref. Dulcídio Cardoso, 1500 / 1504

22640-085 Rio de Janeiro RJ - Brasil

E-mail: egasparetto@gmail.com

\section{Funding support}

This study was supported by the FAPERJ - Fundação Carlos Chagas Filho de Amparo à Pesquisa do Estado do Rio de Janeiro and CNPq - Conselho Nacional de Desenvolvimento Científico e Tecnológico

Received 4 July 2009

Received in final form 3 August 2009 Accepted 15 August 2009

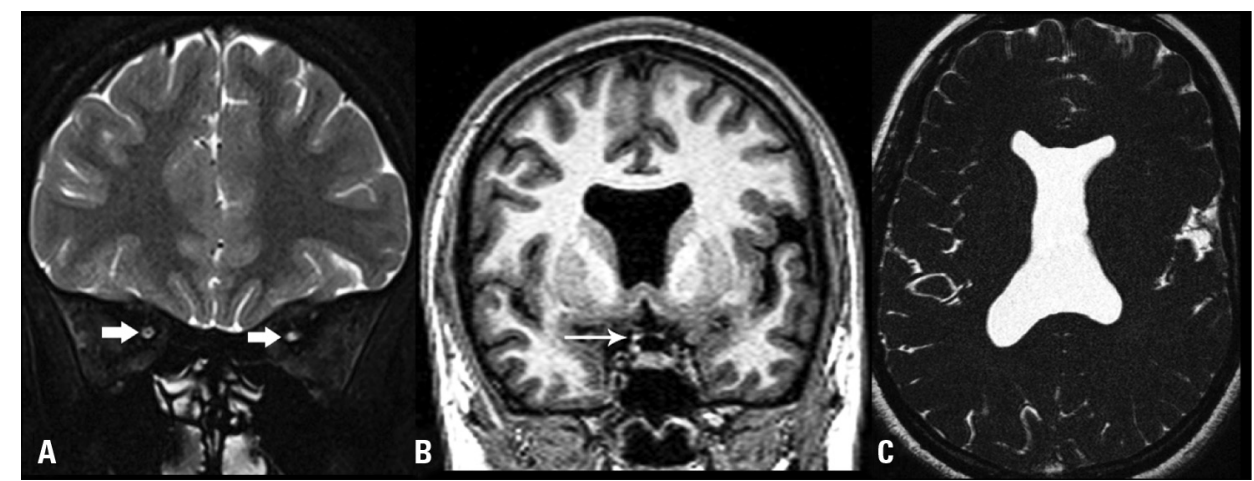

Fig 1. Coronal STIR [A], coronal T1-weighted images [B] and axial CISS 3D (C) demonstrate the hypoplasia of the optic nerves (arrows in A) and chiasm (arrow in B), mainly on the left, as well as complete absence of the septum pellucidum [B and C].

\section{DISPLASIA SEPTO-ÓPTICA PLUS: APRESENTAÇÃO CLÍNICA E ACHADOS NA RESSONÂNCIA MAGNÉTICA}

Department of Radiology and Instituto de Neurologia Deolindo Couto, University Federal of Rio de Janeiro (UFRJ), Rio de Janeiro, RJ, Brazil: 'Médico Especializando em Radiologia e Diagnóstico por Imagem do Instituto de Pós-Graduação Médica Carlos Chagas (IPGMCC), Rio de Janeiro RJ, Brazil; ${ }^{2}$ Médico Residente em Neurologia do Instituto de Neurologia Deolindo Couto, UFRJ; ${ }^{3}$ Médica Residente de Radiologia e Diagnóstico por Imagem do Hospital Universitário Clementino Fraga Filho, UFRJ; ${ }^{4}$ Médico Neurologista do Instituto de Neurologia Deolindo Couto, UFRJ; ${ }^{5}$ Professor Adjunto do Departamento de Radiologia, UFRJ. 


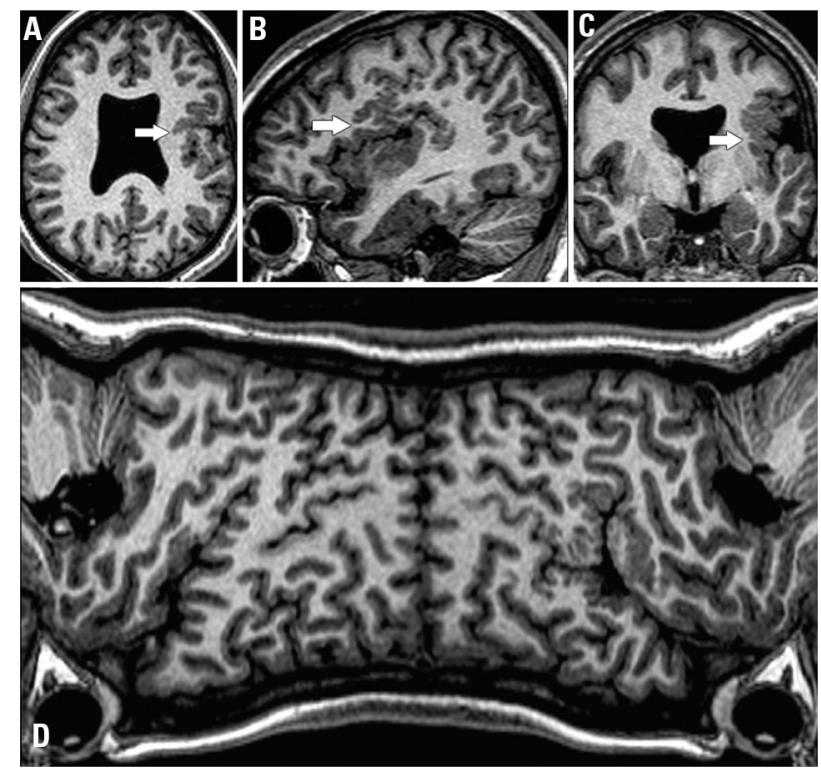

Fig 2. T1-weighted isotropic MPRAGE sequence with reconstruction in the axial [A], sagittal [B], coronal [C] and curved reconstruction [D] show was an extensive area of cortical malformation on the left Sylvian fissure, involving the insula, frontal and temporal lobes, characterized by shallow sulci and slightly thicker cortex, suggestive of polymicrogyria.

of the symptoms. She also mentioned low visual acuity since the childhood, mainly at the left. This symptom was not severe and she could even work regularly as a teacher. No others symptoms, such as diplopia, vertigo, and seizures, or other remarkable past medical history were mentioned. Her gestation and delivery were uncomplicated, and labor was spontaneous at the $30^{\text {th }}$ week. She had no developmental delay or mental retardation. Her family history was not remarkable. The neurological examination showed lateral rectus muscle palsy (VI nerve palsy), Marcus Gunn pupil, and jerky nystagmus on the left eye. The fundoscopy examination showed mild blurring of the right optic pupil, and could not be performed on the left due to technical limitations.

The patient signed informed consent for this study. The brain magnetic resonance imaging (MRI) demonstrated complete absence of the septum pellucidum and hypoplasia of the optic nerves, chiasm and optic tracts, mainly on the left (Fig 1). In addition, there was an extensive area of cortical malformation, characterized by shallow sulci and thickened cortex, suggestive of polymicrogyria, involving the insula, frontal and temporal lobes on the left sylvian fissure (Fig 2).

\section{DISCUSSION}

Septo-optic dysplasia is a developmental malformation that can be characterized by several imaging find- ings such as dysgenesis of the septum pellucidum, hypoplasia of optic nerve and/or chiasma (50\% are normal) and schizencephaly, as seen in our case. The clinical presentation of these patients may range from mild to severe signs and symptoms ${ }^{1-4}$. In 2000, Miller et al. ${ }^{2}$, described three children with global developmental delay and two of then also had spastic motor deficits. On the imaging studies, there was absence of the septum pellucidum and hypoplasia of optic chiasm in all the cases. Only one had unilateral open-lipped schizencephaly and two presented areas of cortical dysplasia (polimicrogyria). As the malformations of cortical development seen were not limited to schizencephaly, the authors proposed the term SOD-plus for these cases. The clinical features of these patients with SOD-plus were distint from the classical form of SOD due to the presence of significant global developmental delay and motor deficits. Since this first report, several cases of SOD-plus were published, all of them associated with severe clinical sings and symptoms ${ }^{3,4}$.

Nevertheless, Kwak et al. ${ }^{5}$ reported an oligosymptomatic case of SOD-plus with the first attack of generalized tonic type seizure lasting for one minute at the age of 29. The patient had no developmental delay or mental retardation and no other remarkable past medical history. Ophthalmological examination revealed bilateral optic disc hypoplasia, amblyopia and bilateral optic nerve lesions. The MRI showed total absence of septum pellucid, bilateral optic nerve hypoplasia, and thickening of bilateral insular cortex without schizencephaly. Similarly, our patient had no symptoms of cortical dysfunction, presenting only headaches and low visual acuity. However, the MRI demonstrated, in addition to the classical findings of SOD, an extensive area of cortical malformation, suggestive of polymicrogyria, involving the insula, frontal and temporal lobes on the left Sylvian fissure.

In summary, although SOD-plus was described in patients with severe symptoms, such as seizures and delay in the motor development, this report corroborates the hypothesis that this syndrome can also be seen in asymptomatic patients, despite the extensive imaging abnormalities.

\section{REFERENCES}

1. Lau KY, Tam W, Lam PK, Wood BP. Radiological cases of the month. Septooptic dysplasia (De Morsier syndrome). Am J Dis Child 1993;147:71-72.

2. Miller SP, Shevell MI, Patenaude Y, et al. Septo-optic dysplasia plus: spectrum of malformations of cortical development. Neurology 2000;54:1701-1703.

3. Camino R, Arjona A. Septo-optic dysplasia plus: case report. Lancet Neurol 2003;2:436.

4. Gasparetto EL, Warszawiak D, Carvalho-Neto A, Benites-Filho PR, Bruck I, Antoniuk S. Septo-optic dysplasia plus: case report. Arq Neuropsiquiatr 2003; 61:671-676.

5. Kwak JG, Jung S, Kwon SB, Hwang SH, Lee BC, Kwon KH. A patient with septo-optic dysplasia plus. J Neurol Sci 2008;264:166-167. 